\title{
IDENTIDADES POLÍTICAS JUVENILES EN SECTORES POPULARES EMERGENTES EN CONTEXTO DE INFORMALIDAD Y TRANSGRESIÓN ${ }^{1}$
}

\author{
Rubén Ticona FERNANDEZ DÁVILA \\ Universidad Ricardo Palma \\ ruben.ticona@urp.edu.pe
}

\section{RESUMEN}

Desde el año 1990 - 2020 se ha profundizado la informalidad y la precariedad en la sociedad peruana, transformando no solo el campo económico sino tambien las formas de pensar y hacer política. En tal sentido, la nueva identidad política popular se redefine desde nuevas coordenadas históricas: el neoliberalismo, informalidad y la precariedad en un contexto cultural marcado por la expansión de la transgresión dan surgimiento a nuevas sensibilidades, valores y aspiraciones de un nuevo individuo político que hoy halla una nueva forma de expresión y representación política. El objetivo del artículo es analizar las nuevas identidades políticas juveniles que estan emergiendo en los sectores populares. La metodología utilizada ha sido cualitativa, se realizaron 16 entrevistas a profundidad en San Juan de Lurigancho en el 2019.

\section{PALABRAS CLAVES}

Identidad política, informalidad, cultura transgresora, sectores populares.

\section{YOUTH POLITICAL IDENTITIES IN EMERGING POPULAR SECTORS IN A CONTEXT OF INFORMALITY AND TRANSGRESSION}

\section{ABSTRACT}

Since 1990 - 2020 informality and precariousness have deepened in Peruvian society, transforming not only the economic field but also the ways of thinking and doing politics. In this sense, the new popular political identity is redefined from new historical coordinates: neoliberalism, informality and precariousness in a cultural context marked by the expansion of transgression give rise to new sensibilities, values and aspirations of a new political individual who today it finds a new form of expression and political representation. The objective of the article is to analyze the new youth political identities that are emerging in the popular sectors. The methodology used has been qualitative, 16 in-depth interviews were conducted in San Juan de Lurigancho in 2019.

1 La presente investigación forma parte de la tesis doctoral en preparación en la Universidad Nacional Mayor de San Marcos titulada Cultura política y fujimorismo en sectores populares 2016-2020. 


\title{
KEYWORDS
}

Political identity, informality, transgressive culture, popular sectors.

Recibido: 20/03/2020

Aprobado: 19/05/2020

\section{INTRODUCCIÓN}

\begin{abstract}
- I presente artículo está dividido en tres partes en la primera se realiza una breve revisión histórica, con la finalidad de presentar las nuevas coordenadas sociales, políticas y culturales que define el contexto histórico desde el cual los sectores populares jóvenes piensan y hacen política.
\end{abstract}

La segunda explora desde las entrevistas realizadas a los jóvenes las nuevas sensibilidades, valores y aspiraciones de un nuevo individuo político para identificar y explicar la identidad política emergente en los sectores populares de San Juan de Lurigancho, las cuales han surgido como expresión de una nueva cultura política popular. Finalmente se desarrolla un conjunto de reflexiones acerca de las consecuencias para la democracia de estas nuevas identidades políticas que se expanden aceleradamente en la ciudad.

\section{CONTEXTO HISTÓRICO}

El modelo neoliberal vigente y el fenómeno de la globalización entre sus diversos impactos políticos ha afectado la forma de hacer política tradicional, generando una forma de "descentramiento" de la política, en el sentido, que refiere Lechner, (1995) quien manifiesta que la centralidad de la época esta marcada por el mercado como forma de organizar la vida social. Lo cual, nos sitúa en un escenario inédito en la historia política, donde las formas de hacer política tradicionalmente tambien han pasado por transformaciones, pues han sido desplazadas de la arena pública hacia su mediatización a traves de los diversos medios y redes de comunicación, fenómeno que en la actualidad es de alcance global. Mattelart, (1998) Castells, (1997).

En consecuencia, estos medios de comunicación adquirieron un rol protagónico en la existencia social y política de la sociedad, paralelamente a este ascenso de la pantalla como filtro de las nuevas formas de hacer política, se produjo el fenómeno de la espectacularización de la política, como parte consustancial a la sociedad del espectáculo, el cual es ampliamente descrito por Schwartzenberg, (1977) y Edelman, M. (1991). De manera que la forma de hacer política y la política misma se han transformado y han terminado por adaptarse como publicidad, farándula y escandalo dirigido a las teleaudiencias. 
Ahora bien, la importancia de abrir un debate es importante, porque losmedios de comunicación se han convertido en actores fundamentales para el proceso político. Verón (1989) Castells, (2009). De ese modo, se han llegado a generar determinadas concepciones como, por ejemplo, la democracia de audiencia, Manin (1992)². De ahí la vigencia de observar al nuevo individuo del siglo XXI, más que como un ciudadano, como un consumidor de la opinión teledirigida, la nueva realidad de la representación democrática podría definirse en términos, como los de videopolítica y política teledirigida, Sartori (1998). Para bien o para mal, la televisión y las redes sociales del internet han influido y modificado sustancialmente la cultura política en la sociedad.

No obstante, aún en las sociedades contemporáneas no podemos negar que el discurso político ocupa un lugar esencial, como fabricantes de lealtades política a veces temporales en otras algo más duraderas, especialmente en un contexto de farandulización y personalización de la política, que en cierto modo, se ha instalado como parte de las prácticas y discursos políticos de un nuevo escenario, fenómeno que se aprecia con mayor nitidez en el Perú desde la década de 1990. Asimismo, otro aspecto a considerar son los partidos políticos, que continúan inmersos en una profunda crisis de representación Lynch (1999) (2000). Este sistema de partidos actualmente se encuentra desacreditado con una deslegitimación frente a la sociedad, y por lo tanto la democracia muestra formas débiles de desarrollo, con liderazgos débiles que devienen en formas caudillistas.

De manera, que se ha despolitizado la vida social, diluyendo lo político e ideológico y sumergiéndole en el vacío del guion para la televisión, privilegiando la imagen mediática y del marketing político como el nuevo fundamento. Este escenario inédito como la nueva realidad social y política del Perú contemporáneo, se combina adicionalmente con características singulares de la cada vez mas compleja realidad, que se encuentra atravesada por una diversidad de fenómenos, entre los que podemos destacar, una elevada tasa de informalidad, precariedad y una mayor presencia de una cultura transgresora, con altos niveles de corrupción e impunidad, que impactan social y políticamente en la sociedad y en los modos de vida de los peruanos.

Se ha producido una desinstitucionalización de la sociedad peruana y que, como proceso en curso termina expresando ese atomismo social que indica Cotler, (2011) del cual pueden emerger formas mayoritariamente, cada vez más antidemocráticas. Las causas de este atomismo social, según Cavarozzi. (2000), se caracteriza por una des-integración de la ciudadanía y la desubicación de los actores políticos, puesto que, a más sociedad civil, puede significar más atomización y anomia, así como a más democracia política, mayor apatía y vaciamiento de la política.

2 Bernard Manin popularizó el concepto de democracia de audiencia para dar cuenta de lo que él comprendía por la era de la tercera gran transformación del gobierno representativo. Esta nueva democracia de audiencia reemplazaba a la democracia de partidos y entre sus aspectos más destacados estarían: el realce de los líderes políticos (personalización), el surgimiento de una ciudadanía pasiva, la transformación de los partidos en una maquinaria electoral, el surgimiento del voto emocional. En suma, la dependencia. 
Esta nueva situación responde a una nueva forma de hacer política, basado en la sociedad del espectáculo, la del control político mediático, que expresa y constituyen los fundamentos mismos

También hay que considerar que desde la década del 90 se produjo la expansión y la hegemonía del discurso neoliberal, el cual lo podemos apreciar con mayor nitidez en el discurso del emprendedor, que reduce lo político y anula lo colectivo, para dar paso al pragmático y al proyecto individualista de autogerenciarse desde los emprendimientos individuales. A esta nueva realidad histórica, hay que agregar el contexto reciente en la cultura política peruana, que está dado por la emergencia de un individuo político inédito en la historia política del país, replegado en la esfera privada de la inmediatez de sus propios problemas personales. Este individuo político cambió radicalmente dejo de ser el luchador sindical, social y vecinal entre los años 1960 - 1980 para convertirse en un individuo pragmático y transgresor desde la década del 90. En suma, en la actualidad tenemos la licuefacción del sujeto político en la ciudad y la emergencia de un individuo político, no en el sentido del liberalismo de la construcción de un ciudadano del proyecto moderno sino se trata, por el contrario, de la construcción de un individuo político indiferente aislado y atomizado, sin compromiso con su comunidad política, que es capaz inclusive de ser transgresor y cínico, hasta de transigir con la corrupción como una opción válida para alcanzar su satisfacción personal.

En resumen, se ha producido un desplazamiento social y político que ha generado una nueva cultura política, nuevas sensibilidades, valores y aspiraciones. En la población emergen nuevas identidades políticas, que ya no son más las identidades políticas sólidas, fuertemente reivindicativas en lo social, económico y político de los años de 1960-1980, ni tampoco esa etapa entre los años de 1990 - 2000, periodo que estuvo caracterizado por el apoliticismo y el clientelismo, como formas de hacer política. En el inicio del siglo XXI, surge un nuevo individuo político, una población que emerge con otros elementos identitarios claramente diferenciados de generaciones anteriores.

La sociedad peruana está atravesando por procesos intensos de transformación social, política y económica, los cuales han rebasado la institucionalidad del Estado y la sociedad. Configurando una débil ciudadanía y muy heterogénea estructuralmente en la ciudad, en donde las demandas sociales están en constante fricción y tensión respecto de la respuesta institucional del Estado, originando una sociedad marcada por la inestabilidad de su sistema democrático, malestar social, precariedad laboral y la debilidad de sus instituciones. Este escenario se configuró históricamente en el Perú, producto de que el contexto cultural, las estructuras sociales, económicas y políticas dieron como resultado un limitado desarrollo democrático, que se vio constantemente acechado y asaltado por autoritarismos y clientelismos políticos.

Lo que trajo como consecuencia que la institucionalidad, no haya madurado como proyecto y ha estado continuamente asediada por la informalidad y la ilegalidad en las tres últimas décadas, desinstitucionalizando continuamente el país. Por lo 
tanto, la democracia ha resultado ser un modelo muy débil, los partidos políticos sin mayor capacidad de representación, los movimientos sociales muy dispersos, en este contexto los discursos políticos se transformaron en guiones o libretos manipulatorios para audiencias y/o públicos cada vez menos exigentes con los contenidos y los programas, de forma que se terminó vaciando el sentido del discurso y la praxis política, y con ambos, simultáneamente la democracia. Ahora solo hay espectros de representaciones y no representados, de modo que la orientación, contenidos y el proposito de la cultura política, nos permiten entender las tensiones, desencuentros y conflictos permanentes que evidencia el profundo proceso de deslegitimación política en el Perú.

\section{NUEVA IDENTIDAD POLÍTICA E IMPLICANCIAS PARA LA DEMOCRACIA}

Por lo señalado líneas arriba, la institucionalidad tiene poco desarrollo y la cultura política se nutre de una baja orientación democrática hacia el sistema, en consecuencia, es muy probable que la "cultura transgresora" que se ha expandido en el país como forma de comportamiento, hoy sea un componente paralelo, que termina por sobrepasarla capacidad del sistema social de conviviry asimilarla dentro de un marco democrático. Como consecuencia se genera un malestar social, se instala de esta forma, un modo de vida y un discurso disruptivo altamente conflictivo y transgresor, todo esto se produce en un contexto de pérdida del horizonte de los sectores populares, quienes se debaten más en la inmediatez de sus necesidades cotidianas que en proyectos colectivos.

El problema de fondo es la insatisfacción con la democracia, la percepción que el Estado y sus instituciones son manejados por intereses personales sea de gente poderosa o de mafiosos, tienen la autopercepción de que su posibilidad de influir o modificar esta realidad los sobrepasa. De manera que emerge una actitud de aprobación de un gobierno fuerte de "mano dura", que prometa resultados frentea los diversos problemas sociales. Como lo describe Portocarrero (2010) siempre buscamos al jefe, al patrón, a la autoridad. Porque en nuestro imaginario nacional existe todavía la idea/actitud del patrón y del siervo.

En este sentido, la cultura política popular se conecta a la búsqueda del caudillismo, paternalismo y mesianismo presente en la historia política peruana y que en la actualidad se ha reforzado políticamente a partir de la informalidad y el pragmatismo clientelar que se asentó más que la formalidad e institucionalidad democrática en las últimas décadas, lo que generó entre otras consecuencias, desconfianza y baja participación. Estos serían algunos de los clivajes culturales que operan en la realidad y permiten la transmisión y reproducción del autoritarismo transgresor, por los cuales ha mantenido vigencia en el imaginario popular de la población. Asimismo, porque se articula a las nuevas identidades políticas que han emergido en los sectores populares. Identidades políticas polimorfas que hallan su expresión y representación en proyectos políticos "neopopulistas" neoliberales, o en proyectos políticos "informales emprendedores", que se han expandido en un contexto cultural transgresor y de una racionalidad neoliberal y cínica instalada en la ciudad. 
En las últimas décadas emergió un nuevo individuo desafectado de la política, subsumido e identificado con la antipolítica, todo ello inmerso en un contexto social neoliberal y de cultura informal, del achoramiento y la criollada como forma de vida, que ha marcado un acelerado proceso de desinstitucionalización de la sociedad y del cual estos sectores populares de San Juan de Lurigancho han absorbido en parte sus nuevos rasgos identitarios, que caracterizan su cultura política.

Finalmente es necesario señalar que la cultura política de los sectores populares y el nuevo individuo político que ha surgido en la ciudad, evidencian un malestar cada vez más creciente con los poderes del Estado y sus autoridades, así como con el sistema político en general al cual lo consideran corrupto e ineficiente, puesto, que no logran resolver los principales problemas. En este sentido, muestran, su indiferencia y rechazo a la política, lo cual abre dos tipos de actitudes políticas, por un lado declaran estar muy poco o nada interesados en política y que sólo se interesan en la política durante las coyunturas de elecciones y en muchos casos su participación se restringe al sufragio por ser este un voto obligatorio y por otro lado la sensación del hartazgo y el desprecio que sienten hacia la política en general, puesto que no funciona para ellos, pero sí para unos cuantos que se benefician de él, como los mismos políticos y su entorno.

En este sentido, los jóvenes de San Juan de Lurigancho son la expresión de una ciudad caótica y de una sociedad precarizada y desigual, en este contexto de alta fragmentación social, hay una mayor presencia de Identidades políticas polimorfas, que debilitan el modelo democrático. De modo que ha surgido un individuo político, que puede transigir con algunos niveles de corrupción o legitimarla, así como también, ha surgido un individuo que desprecia y rechaza todo lo político y los políticos. En suma, la identidad político popular se ha transformado y con el los fundamentos culturales de la política peruana.

La persistencia de la desafeccion por la politica tradicional y el mantenimiento de la debilidad de los vinculos sociales y afectivos entre los ciudadanos y la esfera política cada día son más determinantes y evidentes. Este individuo se halla sumergido más en sus necesidades elementales, que en los asuntos públicos. Su lealtad electoral es variable según el líder o caudillo político que aparezca en el escenario electoral. Es por ello, que estos sectores populares portan identificaciones políticas móviles. De manera, que establece sus vínculos sociales mas cercanos con aquel que represente un discurso y una práctica política pragmática, clientelar y caudillista, porque está más anclado a su entramado cultural y modo de vida.

En suma, esta combinación política, social y cultural pone a la democracia en riesgo permanente de caer en una "tentación autoritaria", lo cual se expresa en una tendencia autodestructiva en el sistema político peruano, que se conduce hacia una mayor fragmentación y confrontación política, que fluctúa entre lo democrático y lo autoritario, como lo atestigua la historia política peruana. 


\section{A MODO DE CONCLUSIONES}

Finalmente, es necesario señalar la constatación de que estamos en un proceso de tránsito hacia nuevas formas de cultura política, que cada vez más, pasan por una mayor intensificación de procesos de desafección hacia la política y lo político, la quiebra de la institucionalidad, la mayor presencia de un sentido común pragmático y transgresor, pérdida de confianza interpersonal e institucional y la expansión en la sociedad de un discurso vaciado de sentido. Estamos pues, entrando a un proceso anómico de posiciones por un lado, cada vez más transgresoras y cínicas y por otro lado, de posiciones confrontacionales y violentas en las relaciones de los distintos actores sociales y políticos, relaciones que se van agudizando y que será lo habitual de nuestra sociedad durante los siguientes años. Todo lo cual conduce inevitablemente hacia formas cada vez más autoritarias en el sistema social y que probablemente podrían desembocar en nuevos autoritarismos como modelo político o de proyectos autoritarios revestidos de formalidad democrática ${ }^{3}$

Tan urgente como aprender a decir nosotros en el sentido de identificarnos y convivir como una comunidad política de iguales, es el tener que re-politizar y re-fundar la política, quizá como la única oportunidad viable de reconstruir el espacio público y el bien común, que se lo han apropiado poderes de facto, como corporaciones y mafias que socavan la posibilidad del desarrollo. En suma, para estos tiempos de crisis y confusión, es necesario re-encantar la vida social, así como de salvaguardar y renovar la democracia para garantizar calidad de vida para la sociedad, se trata de devolver el sentido a la política y a las palabras.

\section{BIBLIOGRAFÍA}

Castells, M. (1997). La era de la información, Vol. II., Madrid: Alianza.

Castells, Manuel (2009). Comunicación y poder. Madrid: Alianza Editorial.

Cavarozzi, M. (2000). El capitalismo político tardío y su crisis en América Latina. Rosario: Homo Sapiens.

Cotler, J. (2011). Capitalismo y Democracia, La tentativa autoritaria. En: “Perú ante los desafíos del siglo XXI": Luis Pasara, ed. Lima. PUCP.

Edelman, M. (1991). La construcción del espectáculo político. Buenos Aires: Manantial.

Lechner, N. (1997). "El malestar con la política y la reconstrucción de los mapas políticos", en Winocur, Rosalía (coord.), Culturas políticas a fin de siglo, México D.F.: Juan Pablos Editor- FLACSO

3 Al respecto véase el trabajo de Shedler, (2016). En su texto: La política de la incertidumbre en los regímenes electorales autoritario, en donde plantea la idea de que los regímenes autoritarios son capaces de establecer todas las instituciones formales de la democracia representativa y no obstante ser autoritarios en su esencia. 
Lynch, N. (1999). Una tragedia sin héroes, la derrota de los partidos y el origen de los independientes: Perú 1980-1992, Lima: Universidad Nacional Mayor de San Marcos, fondo editorial.

Lynch, N. (2000). Política y antipolítica en el Perú. Lima: Centro de estudios y Promoción del desarrollo. Lima: (DESCO).

Manin, B. (1992). Metamorfosis de la representación. Buenos Aires Caracas: CLACSO-Editorial Nueva Sociedad.

Mattelart, A. (1998). La Mundialización de la comunicación. Barcelona: Ed. Paidós,

Portocarrero, G. (2010). Rostros criollos del mal. Cultura y transgresión en la sociedad peruana. Lima: Red para el desarrollo de las ciencias sociales en el Perú.

Sartori, G. (1998). Homo videns. La sociedad Teledirigida. México: Taurus.

Shedler, A. (2016). La política de la incertidumbre en los regímenes electorales autoritario, México: FCE.

Schwartzenberg, R. (1978). El show político: ensayo sobre, y contra el star-system en política. Traducción de Carí Sanz Barberá. Políticos. S. XX. Barcelona: Dopesa.

Verón, E. (1998).“Mediatización de lo político. Estrategias, actores y construcción de los colectivos", en Gauthier, Gilles, Gosselin, André y Mouchon, Jean (comps), Comunicación y política. Barcelona: Gedisa. 